\title{
Adaptation and rebuilding movements of young football players, taking into account different typologies
}

* Georgiy Polevoy ${ }^{1}$

Sri Lanka Journal of Child Health, 2018; 47: 223-227 training required to improve the ability to adapt and rebuild the movement of young football players.

DOI: http://dx.doi.org/10.4038/sljch.v47i3.8543

(Keywords: Typology, football players, nervous system, differentiated approach)

To investigate the influence of typology on the training of young football players on the ability to adapt and rebuild their movement during the game.

Method: Thirty two football players, 11-12 years old, participated in the study. Sixteen football players were used as the experimental group (EG) to improve the ability to adapt and rebuild the movements. The other 16 players made up the control group (CG). In the EG players with a strong nervous system ( 8 persons), intensity of the training load was increased but the volume was decreased. For players with a weak nervous system (8 persons) the volume was increased but not the intensity.

Results: After 8 months of the experiment, there was a significant increase in the ability to adapt and rebuild in football players in the EG. In football players with a strong nervous system, indicators improved from $12.1 \pm 0.3$ seconds to $10.0 \pm 0.2$ seconds $(p<0.05)$, and in football players with a weak nervous system from $12.1 \pm 0.8$ seconds to $9.9 \pm 0.4$ seconds $(p<0.05)$. In the control group too, improvement occurred but the changes were not statistically significant $(p>0.05)$.

Conclusion: The study showed the effectiveness of the use of the typological properties of the nervous system as a method of determining the type of

\footnotetext{
${ }_{1}^{1}$ Associate Professor, Department of Physical Education, VyatGGU and Coach, VyatGGU national football team, Vyatka State University, Kirov, Russian Federation

*Correspondence: gera_lider1@mail.ru
}

(Received on 06 September 2017: Accepted after revision on 27 October 2017)

The author declares that there are no conflicts of interest

Personal funding was used for the project.

Open Access Article published under the Creative

Commons Attribution CC-BY CC. (P)

\section{Introduction}

The formation technique of an athlete depends on the level of development of coordination abilities ${ }^{1,2,3}$. One of the most important coordination abilities for a football player is his ability to adapt and rebuild the motion according to the changing situation on the field during games $^{4,5,6}$. The most favourable period for the development of all coordination abilities is primary school age. The ability to adapt and rebuild movements more intensively develops at the age of 11-12 years y, $^{7,9}$.

The ability to adapt and rebuild motor actions of the player is manifested in the rapidity of conversion of the developed forms of motion or switching from one motor action to another due to changing conditions ${ }^{10}$. To make maximum use of the internal reserves of athletes to reveal their characteristics, training activity must use an individualised approach. In training child athletes, the athletes must be divided into groups according to some unifying characteristic. Criteria for the differentiation of athletes may be different. They can be divided into groups based on their somatic types, functional indicators, the level of technical training etc. ${ }^{11,12,13}$. A little known, but effective criterion for the separation of athletes into groups is the typological approach. Training athletes according to the typological features of display properties of the nervous system has a positive effect on the final result. Such studies have been conducted on athletes taking part in athletics, table tennis and basketball ${ }^{14,15,16}$. However, in football, such studies are sparse.

\section{Objective}

To investigate the influence of typology on the training of young football players on the ability to adapt and rebuild their movement during the game. 


\section{Method}

The study was conducted in Russia, in the city of Kirov, in a Children's and Youth Sports School No. 5. All procedures performed in studies involving human participants were in accordance with the ethical standards of the institutional and/or national research committee and with the 1964 Helsinki declaration and its later amendments or comparable ethical standards. Informed consent was obtained from all individual participants included in the study.

This is a pedagogical experiment comprising determination of the strength of the nervous system in the initiation and determination of the level of development of the ability to adapt and rebuild motor actions. Before the start of the experiment, 32 football players, 11-12 years of age, of Children's and Youth Sports School No. 5, Kirov, were selected by random sampling taking into account the strength of the nervous system. They were divided into the experimental group (EG) and the control group $(\mathrm{CG})^{17}$. Within 8 months the players of $\mathrm{CG}$ were engaged in the usual programme $^{18}$, and the football players of the EG were engaged in the experimental method. In training for football in the $\mathrm{EG}$ a differentiated approach was used based on the typology of the nervous system. The experiment was carried out with players training for 90 minutes every workout.

The strength of the nervous system was determined by the "Tapping-test": A sheet of A4 paper was divided into six squares, three squares in two rows. At the signal, the athletes put the dots in one square every 5 seconds with the command to move to the next square. They needed to quickly put as many dots in each square. After the sixth square the exercise ended. The result, counting the number of dots in each square, built the schedule of performance. The test is scheduled to determine the type of strength of the nervous system ${ }^{19}$.

The ability to adapt and rebuild motor actions of football players was determined by the test, "Running between the sticks": In a straight line at a distance of 2.5 metres from each other were installed 3 sticks. The first stick was at a distance of 2.5 metres from the start. At the signal, the athlete dribbles one leg between the sticks. Athlete passes each stick using the right leg and then left leg. The measurement accuracy is 0.01 seconds $^{10}$.

Two friendly matches were played between the EG and the $C G$ before and after the experiment

\section{Feature training in the $E G$}

1. After warm-up for 20 minutes, the football players in the EG performed exercises on developing the ability to adapt and rebuild in different subgroups: the game involves dribbling the ball with an unexpected attack from the side, running with changes of direction and speed, tackling in pairs, loss of balance with a partner, and many others $^{10,20}$.

2. Methods of exposure: repeated, variable, game and competitive methods ${ }^{1,10,20}$.

3. Methodical receptions: the introduction of new exercises or old exercises of increasing complexity, change, speed and direction of the exercise $e^{1,10,20}$.

4. The main difference in training football players with strong and weak nervous system were components of the load. For players with a strong nervous system, the load intensity was increased but the volume was decreased. For players with a weak nervous system the volume was increased but not the load intensity ${ }^{14,15,16}$.

The load intensity was increased by increasing the amount of exercise and decreasing the rest intervals and the volume was increased by increasing the number of repetitions and rest intervals. The intensity of the exercise for players with a strong nervous system was $170-180$ beats per minute, and for players with a weak nervous system 140-150 beats per minute. The duration of the exercise for the football players with a strong nervous system was 20-30 seconds and 30-40 seconds for those with a weak nervous system. In both groups the rest time lasted until full recovery, the character of recreation being passive. The number of repetitions of one exercise in football players with a strong nervous system was 3-5 times, and in those with a weak nervous system 4-6 times. The number of training sets was 6-8 for players with a strong nervous system and 7-10 for those with a weak nervous system.

The players of the control group had short warm-up exercises on the technique. The intensity and volume of exercise were the same for all players in the control group regardless of the strength and weakness of the nervous system.

\section{Statistical analysis}

Mathematical and statistical processing of experimental results was performed using parametric tests (student- $t)^{21}$. Correlation analysis was performed using the software Bio Stat 2009 programme. The result was considered significant at a value of $p<0.05^{22}$.

\section{Results}

Prior to beginning the pedagogical experiment, a friendly match was played between the EG team 
and the $\mathrm{CG}$ team. The match ended with a minimum advantage to the CG team $0-1$. Objectively it was clear that the football players in both groups move about the same and equally possess the capacity to adapt and rebuild motor actions during the game.

Players in both groups performed a control test "Running between the sticks", which shows the level of development of the ability to adapt and rebuild motor actions of young football players. Before the beginning of the experiment, the players' performance corresponded to the average level of development of the ability to adapt and restore the motor actions of football players of 11-12 years ${ }^{10}$. Indicators of capacity to adapt and rebuild motor actions of football players 11-12 years are shown in table 1 .

Table 1

Indicators of capacity to adapt and rebuild motor actions of football players 11-12 years old (M $\pm m$ )

\begin{tabular}{|c|c|c|c|c|c|c|c|c|}
\hline \multirow{3}{*}{ Indicators } & \multirow{3}{*}{$\begin{array}{c}\text { Strength of } \\
\text { the nervous } \\
\text { system }\end{array}$} & \multicolumn{3}{|c|}{ EG } & \multicolumn{3}{|c|}{$\mathrm{CG}$} & \multirow{3}{*}{$p(2-5)$} \\
\hline & & Before & After & $p$ & Before & After & $p$ & \\
\hline & & 1 & 2 & 3 & 4 & 5 & 6 & \\
\hline \multirow{3}{*}{$\begin{array}{l}\text { Kicking the } \\
\text { ball into the } \\
\text { target (Amount } \\
\text { of points) }\end{array}$} & Strong & $12.1 \pm 0.3$ & $10.0 \pm 0.2$ & $\begin{array}{l}\mathrm{t}=6.08 \\
p<0.05\end{array}$ & $12.4 \pm 1.3$ & $11.9 \pm 0.8$ & $\begin{array}{l}\mathrm{t}=0.35 \\
p>0.05\end{array}$ & $\begin{array}{l}\mathrm{t}=2.38 \\
p<0.05\end{array}$ \\
\hline & Weak & $12.1 \pm 0.8$ & $9.9 \pm 0.4$ & $\begin{array}{l}\mathrm{t}=2.19 \\
p<0.05\end{array}$ & $12.6 \pm 0.6$ & $12.4 \pm 0.4$ & $\begin{array}{l}\mathrm{t}=0.36 \\
p>0.05\end{array}$ & $\begin{array}{l}\mathrm{t}=4.25 \\
p<0.05\end{array}$ \\
\hline & & $\begin{array}{l}\mathrm{t}=0.05 \\
p>0.05\end{array}$ & $\begin{array}{l}\mathrm{t}=0.15 \\
p>0.05\end{array}$ & - & $\begin{array}{l}\mathrm{t}=0.15 \\
p>0.05\end{array}$ & $\begin{array}{l}\mathrm{t}=0.58 \\
p>0.05\end{array}$ & - & - \\
\hline
\end{tabular}

After the training, in the $\mathrm{CG}$ the performance increased but the improvement was not significant. In players with a strong nervous system, indicators improved from $12.4 \pm 1.3$ seconds to $11.9 \pm 0.8$ seconds $(p>0.05)$ and in players with a weak nervous system indicators improved from $12.6 \pm 0.6$ seconds to $12.4 \pm 0.4$ seconds $(p>0.05)$.

After the training, in the EG performance improved significantly. In football players of EG with strong nervous system indicators improved from $12.1 \pm 0.3$ seconds to $10.0 \pm 0.2$ seconds $(p<0.05)$, and in players with a weak nervous system from $12.1 \pm 0.8$ seconds to $9.9 \pm 0.4$ seconds $(p<0.05)$. These figures correspond to the high level of development ability to adapt and rebuild motor actions of football players for age 11-12 years ${ }^{10}$.

After the pedagogical experiment the teams of EG and $\mathrm{CG}$ once again played a friendly match among themselves. The game ended with a confident victory of football players of EG 4-0. The football players from team EG looked much more skilled, quickly adaptable to changing situations and able to rebuild their actions more effectively than the football players of CG. This result allows judging the effectiveness of the methods used. The physiological basis for improving the productivity, technical training of young players is the strength of their nervous system in the process of excitation. For players with a weak nervous system, the load will be more intensive and less voluminous whilst for players with a weak nervous system, the load will be more voluminous and less intensive.

\section{Discussion}

The level of development of coordination abilities of a football player is the foundation of his technical skill. Among the many coordination abilities, the ability to adapt and rebuild movements is necessary in game activity of players of different ages ${ }^{7,8,9}$. Most studies, which aim at studying the coordination abilities of the football players determined the total load for all players ${ }^{14,15,16}$. Some studies have identified methods and physical exercises that are effective means of development of coordination abilities ${ }^{1,10,20}$.

This emphasizes the importance and effectiveness of a differentiated approach, which can reveal the possibilities of athletes ${ }^{11,12,13}$. At the same time, today there is a lack of methods that use the differentiated approach, based on typological properties of the nervous system. Although the importance and effectiveness of using typological criteria was emphasized for a long time ${ }^{19,23}$, there is no clear understanding of the tools, methods and the stress components that should be used for the development of abilities of athletes with differentiated typology.

Young football players, who were involved in the experimental method, showed good results in the test "Running between the sticks" and defeated players from CG. The main difference and novelty of the experimental method is typological peculiarities of nervous system properties. For players with a strong nervous system, the load is effective when it is intense, but for players with a weak nervous system volume of load has to be 
increased. In our study, the use of typological features of nervous system properties as a criterion of differentiation of athletes in the group fully met its effectiveness and is supported by studies conducted earlier in other sports ${ }^{14,15,16}$. Confirmed by the fact that in working with athletes with a strong nervous system, you must use an intense workload, and for athletes with a weak nervous system is the volume. This study details the tools and methods that can be used to develop the ability to adapt and rebuild motor actions of football players 11-12 years old.

The purpose of the experiment was to obtain new results and specific recommendations for working with young football players aged 11-12 who have different typological peculiarities of the nervous system properties. The study is of great practical interest for coaches of sports schools, and teachers of schools and higher educational institutions. The study describes in detail the tools, methods, components of load and tests that need to be used in working with young football players.

\section{Conclusions}

The study showed the effectiveness of the use of the typological properties of the nervous system as a method of determining the type of training required to improve the ability to adapt and rebuild the movement of young football players

\section{References}

1. Lyakh VI, Sadowski J, Witkowski Z. Development of coordination motor abilities (CMA) in the system of long-term preparation of athletes. Polish Journal of Sport and Tourism 2011; 3:187-97. https://doi.org/10.2478/v10197-011-00146

2. Jaakkola J, Watt A, Kalaja S. Differences in the motor coordination abilities among adolescent gymnasts, swimmers and ice hockey players. Human Movement 2017; 1:44-50. https://doi.org/10.1515/humo-2017-0006

3. Oskolkov VA, Kshinin II. Coordination abilities in structure of motor possibilities of the young boxers with various tactical manners of the duel conducting. Uchenye zapiski universiteta imeni P.F. Lesgafta 2011; 77:121-4.

4. Alexandrova VA, Shian VV. Some types of the coordination abilities of the athletedancers. Uchenye zapiski universiteta imeni P.F. Lesgafta 2014; 112:12-7.
5. Nikitin AV. Coordination abilities of young football players-goalkeepers in their structure of motor abilities. Uchenye zapiski universiteta imeni P.F. Lesgafta 2011;81:108-12.

6. Dveyrina OA. Coordination capacities: definition, classification, forms. Uchenye zapiski universiteta imeni P.F. Lesgafta 2014; 35:35-8.

7. Feoktistov MF. Periods of sensitivity of development of physical abilities among various contingents of pupils at average school age. Uchenye zapiski universiteta imeni P.F. Lesgafta 2010; 62:118-20.

8. Oskolkov VA, Kshinin II. Boxers` coordination abilities development at different periods of their technical and tactical skills formation. Uchenye zapiski universiteta imeni P.F. Lesgafta 2011; 75:93-96.

9. Karpeev AG. Long-term strategy of sports and technical preparation with due regard for age peculiarities of motor coordination development. Uchenye zapiski universiteta imeni P.F. Lesgafta 2008; 38:35-9.

10. Ljach WI, Witkowski Z. Development and training of coordination skills in 11- to 19year-old soccer players. Human physiology 2010; 1:64-71. https://doi.org/10.1134/S03621197100100 81

11. Sonina NV, Rodin AV. The differentiated approach to technique-tactical preparation of young basketball players of 15-16 years old in view of game role. Uchenye zapiski universiteta imeni P.F. Lesgafta 2008; 38:84-6.

12. Alagizov AV. Differentiated methodology for training of children aged 10-11 years old engaged in winter polyathlon considering their morphological and functional parameters. Uchenye zapiski universiteta imeni P.F. Lesgafta 2012; 92:7-10.

13. Khasawneh A. Prevailing Somatotypes and Their Contribution Rate to the Coordination Abilities among the Students of the Physical Education College. Physical Education 2015; 3:176-87. https://doi.org/10.4236/ape.2015.53022 
14. Makarov YM, Hussain A-T. Typological profile of person properties of the basketball players aged 16-18 years old depending on the style of game activity. Uchenye zapiski universiteta imeni P.F. Lesgafta 2011; 73:122-4.

15. Kostyunina LI, Kiryanova LA, AnisimovaYA. Special features of the manifestation of nervous system typological properties among sprint track and field athletes. Uchenye zapiski universiteta imeni P.F. Lesgafta 2010; 62:38-42.

16. Serova LK, Voronov AA. Dependence of individual style of activity in table tennis on typological properties of the identity of athletes. Uchenye zapiski universiteta imeni P.F. Lesgafta 2013; 95:140-3.

17. Шкляр ВM. Usage of statistical methods in the pedagogical researches. Science Rise 2015; 5:39.

https://doi.org/10.15587/2313-

8416.2015.57049

18. Godik MA. Football: a model of training program of sports training for youth sports schools, specialized youth school of Olympic reserve. Moscow: Soviet Sport 2011. p. 1-160.
19. Strelau J. Pavlov's Nervous System Typology and Beyond. Moscow: Individual differences and psychopathology 1983. p. 139-154.

20. Paramonov VV. Development of abilities to rational activity in the changed conditions of young football players' training. Uchenye zapiski universiteta imeni P.F. Lesgafta 2011; 82:124-7.

21. Oldham J. Statistical tests (Part 2): parametric tests. Nursing Standard 1993; 44:28-30.

https://doi.org/10.7748/ns.7.45.28.s40

22. Feller W. Review: Harald Cramer, Mathematical Methods of Statistics. The Annals of Mathematical Statistics 1947; 1:136-9. https://doi.org/10.1214/aoms/1177730503

23. Nebylitsyn VD. The nature of balance of the nervous properties according to the basic properties of the nervous system. Fundamental properties of the human nervous system. New York: Plenum Press, 1972. p.262-273 